\title{
Persistent vegetative state, withdrawal of artificial nutrition and hydration, and the patient's "best interests"
}

\author{
Raanan Gillon Imperial College School of Medicine, University of London
}

In this issue of the journal Anthea Fenwick, an Edinburgh University graduate law student, robustly challenges the use of "best interests" by English judges in the context of permitting withdrawal of life-supporting nutrition and hydration from patients in persistent vegetative state (PVS). ${ }^{1}$ Judges, she states, have ruled that such life-sustaining treatment can be withdrawn on the grounds of the best interests of a patient in PVS; but this criterion ought to be rejected for four reasons: first, it is based on a "delusory objective": second its foundation is illogical; third, judicial interpretation of the criterion is excessively medically orientated, and fourth such "medicalisation" unduly narrows the acceptable range of potentially relevant interests when considering what are a patient's "best interests".

From a perspective of medical ethics as distinct from medical law - and of course the two overlap Ms Fenwick is surely being somewhat hard on the judges! They, like the medical profession are obliged to act within the law, both statutory and case law. For them, as for doctors, any intentional killing of another person who is not an aggressor is illegal and they are not permitted to change this fundamental legal fact, itself presumably established to uphold the literally vital general moral concern that people's lives should be protected.

However, while intentional killing of nonaggressors is illegal, allowing others to die may be legally permissible and in some circumstances it is clearly right for a doctor not to try to prolong a patient's life, or to cease doing so. This moral fact is widely, probably universally, recognised in law, allowing doctors in some circumstances to withhold, and in some circumstances to withdraw, life-prolonging treatment (LPT).

The justification of such withholding or withdrawing of LPT in medical ethics would most probably be that its provision would not benefit the patient. The primary moral purpose of medicine is to try to benefit people in health-related ways and this is incorporated into a doctor's moral and legal duty of care. Where an intervention is highly unlikely to provide such benefit to the person there is no medico-moral or legal obligation to provide it and withholding or withdrawing it does not infringe the doctor's duty of care. Furthermore where continuing provision of nonbeneficial medical resources deprives others of benefit, there is at least a prima facie moral obligation to withhold or withdraw them.

Thus the first part of the medico-moral argument seems, pace Ms Fenwick and in support of the judges, to be entirely consistent with a judgment that provision of LPT may in some circumstances not be in a patient's best interests, not part of the doctor's duty of care, and thus be legitimately withheld or withdrawn. Note, however, that this conclusion does not entail that LPT would be against the patient's best interests merely that it would not be in that person's best interests. (It is not in my best interests if Jones rather than Smith wins a prize - but neither is it against my best interests).

Can this medico-moral reasoning that in some cases of persistent vegetative state use of lifeprolonging treatment may be "not in the best interests of a patient" (though not necessarily against any such interests) and therefore not morally obligatory withstand Ms Fenwick's specific criticisms? While her detailed and thoroughly argued paper deserves a more extensive reply than is possible here, a brief outline of such a defence follows.

First it may be denied that the "not in the best interests" argument is based on "a delusory objective". Ms Fenwick argues that since the patient's death is the inevitable consequence of withdrawal of LPT in PVS that death must be the agent's "true" objective. But any action is properly described in part by the intentions of the agent; and there is no necessity for the patient's death, though foreseen as inevitable, to be the agent's 
intention. There need be no "judicial delusion" in recognising that the intention of the doctor - and indeed of the judge - may be to withdraw treatment that is not benefiting the patient and is thus not in the patient's interests and thus not in the patient's best interests to provide. A simple test of whether or not the patient's death is the doctor's (or the judge's) true intention is to ask how either would respond if the patient by remote chance woke up and asked for food and water. Of course they would give food and water! Thus there is no reason to insist that the "true" intention in withdrawing LPT is the patient's death - even though such withdrawal will almost certainly be part of the cause of the patient's death (the main cause being the brain damage and its causes that have resulted in the PVS).

Ms Fenwick's second criticism is that the "not in the patient's best interests" justification for withdrawal of LPT is "illogical". If the patient is claimed to have no interests, she argues, "then surely 'best' becomes superfluous - no pool [of interests] exists from which to draw the 'best'. The derivation is, therefore, simply not logical, yet this seems overlooked in judgments thus far". While it would certainly be illogical - because contradictory - to claim that someone had a best interest if he or she had no interests, it is entirely logical, and obviously true, to state that someone who has no interests has no best interests. If such were the case it would logically follow that no treatment could be in that person's best interests.

Her third criticism is that the "not in the patient's best interests" judgment "medicalises" the patient's interests, and by importing the "Bolam" standard of judgment by a responsible body of medical opinion "subjugates patient interests to professional duty...". And her fourth criticism claims that such medicalisation of "best interests" narrows the range of applicable interests, which should, she suggests include a patient's personal interests including such non-medical interests as religious belief, family interests including the views of those emotionally close to the patient, "and even 'societal' interests" such as the effect of a decision on society, on similarly placed patients, and on resource allocation.

Whether or not the judges have in fact inappropriately applied the "Bolam" standard and unreasonably medicalised and restricted the concept of a patient's interests in their judgments will not be addressed here. However, many of the positive claims made by Ms Fenwick in this part of her critique are entirely consistent with contemporary medical ethics and much of her advice can and surely should be incorporated into the manage- ment of patients in PVS. In particular, patien reliably determined prior views should surely tie determinative of their "best interests", whether these views favour or reject LPT.

But while a patient's best interests are the primary moral issue in medical care they are not and cannot be the only issue. Sometimes the interests of others, especially others in need of scarce medical resources - the "societal" interests referred to by Ms Fenwick - may outweigh those best interests. Thus even if some course of treatment would be regarded by a patient as in hig or her best interests, and even if a proper pro confirmed that this would be the patient's view, $\overrightarrow{\bar{\phi}}$ does not automatically follow, morally or legalls that the patient's best interests must be pursued In particular when there are not sufficient healt care resources available to meet everyone's begt interests then judgments both moral and legal may be needed to withhold even strongly desiref resources from one person in order to provide them to others. Particularly in a nationald provided health service with limited resources may be proper to decide against provision of life prolonging treatment for people in PVS beyon an agreed time period. Similar decisions have be made even when patients are entirely conscioss and English courts have supported the right health authorities to make them. ${ }^{2}$ There may wet come a time when a health authority decides apply to a court to withdraw life-prolonging treat ment, including artificial nutrition and hydration, from a patient in PVS despite the patient and/4 the patient's proxies' clear statement that the consider such treatment to be in the patient's best interests. Such a decision might be justified fromi an ethical perspective that took into account the interests of people with competing medical needs, when not all those needs could be met. A court might well support such a judgment by a heal authority. That legal judgment, however, shoud surely not be made on the grounds of the patientos best interests, for by hypothesis the patient's viend should determine his or her best interests. Rathety the decision should be made on the grounds of distributive justice in which treatments that prolong life but with very low probability of resteration of sentience, let alone a life that the patient is able to experience as worth living, should be accorded low priority.

\section{References}

1 Fenwick A. Applying best interests to persistent vegetative stata - a principled distortion? Fournal of Medical Ethics 1998; 84: 86-92.

2 R v Cambridge Health Authority, ex p B [1995] 2 All ER 1238. 